\title{
Prevalence and risk factors of pre-sick building syndrome: characteristics of indoor environmental and individual factors
}

Yoshitake Nakayama ${ }^{1 *}$, Hiroko Nakaoka ${ }^{1}$, Norimichi Suzuki ${ }^{1}$, Kayo Tsumura ${ }^{1}$, Masamichi Hanazato ${ }^{1}$, Emiko Todaka ${ }^{1}$ and Chisato Mori, ${ }^{1,2}$

\begin{abstract}
Background: With the aim to prevent sick building syndrome and worsening of allergic symptoms, primarily resulting from the indoor environment, the relationships among people's residential environment in recent years, their lifestyle habits, their awareness, and their symptoms were investigated using an online survey.

Methods: In the survey, respondents experiencing symptoms specific to sick building syndrome, although they were not diagnosed with sick building syndrome, were categorized in the pre-sick building syndrome group. The relationships among individual characteristics, residential environment, and individual awareness were analyzed.

Results: Results showed that the prevalence of pre-sick building syndrome was high among young (aged 20-29 years) population of both sexes. In addition, "condensation," "moisture," "musty odors" in the house, and the "use of deodorant and fragrance" were all significantly associated with pre-sick building syndrome. Conversely, there was no significant association with recently built "wooden" houses that are highly airtight and have thermal insulation.
\end{abstract}

Conclusions: Efficient "ventilation" plans and "ventilation" improvement and air conditioning systems to prevent mold and condensation in rooms are necessary to maintain a good, indoor environment that is beneficial for health. Efforts should also be made to encourage individuals to regularly clean and effectively ventilate their homes.

Keywords: Air quality, Sick building syndrome, Residential environment, Lifestyle, Online survey

\section{Background}

Till date, many studies have been globally conducted to investigate indoor chemical substances and their influence on health to prevent "sick building syndrome (SBS);" the symptoms of "SBS" include mucosal irritation and allergylike symptoms and are linked to spending time in a specific building [1-11]. In Japan, restrictions have been placed on the concentration of certain volatile organic compounds (VOCs) and total volatile organic compounds generated by implementing values in the indoor concentration guideline by the Ministry of Health, Labour and Welfare, and by the revisions of the building-standard

\footnotetext{
* Correspondence: seiken@chiba-u.jp

${ }^{1}$ Center for Preventive Medical Sciences, Chiba University, 6-2-1 Kashiwanoha, Kashiwa, Chiba 277-0882, Japan

Full list of author information is available at the end of the article
}

laws by the Ministry of Land, Infrastructure and Transport $[12,13]$. However, "SBS" is still persistent. In 2017, the "Manual for Consultation and Countermeasures on Sick House Syndrome Based on Scientific Evidence (revised new edition)" was created by the Ministry of Health, Labour and Welfare Research Group [14], and in 2019, the Ministry of Health, Labour and Welfare further revised the values for xylene, di-n-butyl phthalate, and di(2ethylhexyl)phthalate concentrations in the guidelines [15]. Various indoor factors cause physical ailments, including chemical factors, such as exposure to chemical substances volatilizing from building materials, furniture, and household goods; biological factors, such as mold, ticks, and bacteria; physical factors, such as heat, light, noise, and radiation; and social and psychological factors of residents [16-18]. "SBS" is associated with the awareness of 
residents to improve their indoor air quality by opening windows for "ventilation," cleaning, and lifestyle and with the air environment such as indoor chemical substance concentrations, temperature, humidity, and odor [19, 20]. In addition, recently, owing to the development of new, highly insulated, airtight housing, there is a growing concern of an increase in living spaces where chemical substances are more likely to accumulate compared with conventional houses. Furthermore, a growing, global appreciation for "wooden" architecture and global interest in cross-laminated timber [21], in conjunction with the enforcement of a law by the Japanese government that promotes the use of wooden materials in public buildings [22], may increase the risk of generating unregulated chemical substances due to the development of new building materials, adhesives, paints, and construction techniques [23, 24]. Although studies regarding indoor environments and the onset of "SBS" or allergic symptoms have been conducted in the past [25-27], with changes in the housing environment over time, it is important to continue to investigate and assess the impacts of indoor environments on health. Therefore, we conducted a comprehensive survey using an online questionnaire regarding the occurrence and risk factors of "SBS" to investigate the association between indoor environment accompanying the aforementioned changes in residential environments over time, the characteristics of residents and their awareness regarding air quality and diseases, and "SBS" and allergy-like symptoms, at the Center for Preventive Medical Sciences, Chiba University, in June 2017. The aims of this study are first, to collect data on the relationship between recent living environment and lifestyle as well as "SBS" and allergy-like symptoms; second, to define preSBS according to respondents' experience and the frequency of "SBS" symptoms; and third, to statistically analyze the effects of those environmental and personal factors on pre-SBS people.

\section{Methods}

\section{Data collection}

A nationwide, questionnaire survey was administered to 1500 individuals (750 males and 750 females; age 18-70 years). The survey was implemented over 4 days from June 16 to June 19, 2017. All participants were provided the information that by answering the survey, they will be deemed to consent to cooperate with this study. The survey was conducted by a web research service (Rakuten Research Co., Ltd.) that used random sampling after screening for sex, age, and location of residence. Data from 1500 participants with no missing items were collected and analyzed.

\section{Questionnaires}

The questionnaire comprised 31 questions in total: 13 regarding participant characteristics; 4 regarding SBS-specific symptoms; 12 regarding residential environments, specifically the indoor environment of buildings where participants spent most of their day and had the largest impact on their health; and 2 regarding respondent's awareness of air quality. Questions regarding participant characteristics related to age, sex, years of education, "family income," medical history ["asthma," "atopic dermatitis," "rash," "hay fever," "allergic rhinitis," "allergic conjunctivitis," "food allergy," "urticaria," "SBS," "multiple chemical sensitivity (MCS)," and "mental illness"], "smoking" history, a history of exposure to cigarette smoke, the existence of a newly built residence or workplace, the number of people living at the place of residence, whether living with children, the disease history of family members living together, "sensitivity of family members living together to air quality and odors," and the "smoking" history of family members living together. Questions regarding symptoms concerned general symptoms and mucosal irritation symptoms (eye, nasal, and throat symptoms) $[28,29]$ based on the symptom categories defined by MM040EA, the Japanese version of the MM (Miljumedicin in Swedish) Questionnaire [1]. Specifically, general symptoms included "headache," "heaviness in the head," and "tinnitus" on entering the building, and mucosal symptoms included "eye irritation," "itchy eye," "dry eye," "itchy nose," nasal congestion, rhinorrhea, itchy throat, sore throat, dry mouth, "coughing," and "sneezing." Questions regarding residential environment included the number of years lived in the house, the age of the house, the structure of the house, the "material of bedroom window frames," the "insulating glass pane in the bedroom," the presence of "condensation," the presence or absence of "moisture and mold," odor status, the frequency of "use of deodorant and fragrance" in the house or workplace, the presence or absence of "pets," the frequency with which windows are opened for "ventilation," the "frequency of cleaning," and the location of residence. Questions regarding respondents' awareness of air quality included the presence or absence of an "interest in indoor air quality and odor" and of "SBS." In addition, the air-tightness and thermal insulation performance of residential environments were estimated from the type of window sashes and the number of panes of each window [30]. The type of window sash was scored as follows: 1 point for a "wooden" fitting, 2 points for a regular "aluminum sash," 3 points for an "aluminum double sash," and 4 points for an "insulation sash." The type of window was scored as follows: 1 point for "single-pane glass," 2 points for a "double-pane glass," and 3 points for a "triple-pane glass." The thermal insulation performance of windows was defined based on the combined points as follows: 2 points as prior to the S55 standard (energy-saving standard in 1980), 3-4 as the S55 standard, 5 as the H4 standard (The new energy-saving standard), and $6-7$ as the H11 standard (the nextgeneration energy-saving standard) [31]. 
The protocol of this study was approved by the Research Ethics Committee of the Graduate School of Medicine, School of Medicine, Chiba University (Approval No. 2737).

\section{Definition of pre-SBS}

In this study, we hypothesized that the participants experience SBS-specific symptoms but are not diagnosed either with "SBS" or with "MCS" or that the participants do not seek medical attention due to unawareness of the disease. The lack of awareness due to mild symptoms or exposure to low concentrations of TVOC may lead to exposure for an extended period, ultimately causing severe symptoms and increasing the risk of developing "SBS" [32, 33]. Therefore, those who answered "occasionally," "often," or "always" for experiencing at least one of the symptom categories, when they entered their house building, were considered to have a high risk for "SBS" (pre-SBS group).

\section{Statistical analysis}

To identify the factors linked to pre-SBS, a binomial logistic regression analysis using "pre-SBS" as the objective variable was performed. A total of 1493 participants were included in the analysis after excluding 7 individuals who were previously diagnosed with either "SBS" or "MCS." Multivariate analysis was performed with values of $p<0.05$ being considered as significant; odds ratios and $95 \%$ confidence intervals were also calculated. The presence or absence of multicollinearity between explanatory variables was confirmed using Spearman's rank correlation analysis; "rearing a child (children)" and "number of people living together" were the only variables that showed a correlation coefficient of $\geq 0.4$ at $p<$ 0.05 . Then, in model 1 , the forced entry method was used to analyze the following 18 explanatory variables: sex, age range, years of education, "family income," "asthma," "atopic dermatitis," 'rash," "hay fever," "allergic rhinitis," "allergic conjunctivitis," "food allergy," "urticaria," "mental illness," "smoking" history, the existence of a newly built residence or workplace, "interest in air quality and odor," and the recognition of "SBS" and related diseases. In model 2, the forced entry method was used to analyze 12 items which were used as explanatory variables that related to participants' residential environments: the disease history of family members living together; the "sensitivity of family members living together to chemical substances or odors;" the location of residence, the years of residence in their current house; the building structure of the house; insulation performance standard; the "condensation status of the house;" the conditions of "moisture and musty odors" in the house; the frequency of "use of deodorant and fragrance;" the presence or absence of "pets;" open-window "ventilation;
" and "cleaning frequency." In model 3, the analysis was performed by the stepwise method (likelihood ratio) using a total of 27 items comprising participant characteristics, awareness, and personal environment as explanatory variables and all other factors as adjustment variables, after determining the influence of factors concerning both a participants' characteristics and awareness and their personal environment on the development of pre-SBS. The statistical software package SPSS, version 25.0 for Mac (SPSS Inc., Chicago, IL, USA), was used for all analyses.

\section{Results}

\section{Participants' characteristics}

Participants' characteristics are shown in Table 1, and the key features are described below.

The age range of participants was as follows: $20-29$ years, $4.5 \%$; $30-39$ years, $17.7 \%$; $40-49$ years, $35.5 \%$; 50 59 years, 33.1\%; and 60-69 years, 9.1\%. As "disease history," $0.1 \%$ of participants had "SBS," $0.4 \%$ had "MCS, " and $25.7 \%$ had "hay fever" (the last of which was the most frequent condition to appear in respondents' medical histories). For "smoking" history, 22.7\% of respondents reported having previously smoked but were not currently "smoking," and $24.4 \%$ reported that they were currently "smoking." For symptoms such as "headache," "heaviness in the head," and "tinnitus" that appeared upon entering their building, $12.9 \%, 5.2 \%, 1.6 \%$, and $1.3 \%$ respondents answered "rarely," "occasionally," "often," and "always," respectively. With regard to mucosal symptoms, 13.4-20.7\% answered "rarely," 5.5-10.1\% answered "occasionally," 0.9-2.5\% answered "often," and $0.9-1.0 \%$ answered "always." In response to the question regarding personal environment, $24.9 \%$ of respondents had "a family member living together with sensitivity to chemicals and odor." Moreover, $48.6 \%$ lived in a "wooden" house based on responses to the question regarding the "building structure of the house." Regarding the "condensation" status of the house, 68\% answered that "condensation" existed, and 52.4\% reported the presence of "moisture and musty odor." Regarding the frequency of "use of deodorant and fragrance," $26.1 \%$ of respondents reported not using them at all, $22.9 \%$ reported rare use, $29.3 \%$ reported occasional use, $13.1 \%$ reported frequent use, and $8.6 \%$ reported daily use. Regarding the frequency of opening windows for "ventilation", 73.9\% answered that they did this "more than once/day," and as for "frequency of cleaning," $77.5 \%$ answered that they cleaned "more than once/week." As for awareness, 63.9\% of respondents had an "interest in air quality and odor," while with regard to "recognition of SBS," 51.9\% had heard about it, 30.9\% knew about it, and $8.7 \%$ knew it well. 
Table 1 Participants' characteristics

\begin{tabular}{|c|c|c|c|c|c|}
\hline & Number & $\%$ & & Number & $\%$ \\
\hline Sex & & & Having a child & & \\
\hline Male & 750 & 50.0 & Yes & 876 & 58.4 \\
\hline Female & 750 & 50.0 & Family medical history & & \\
\hline Age (years) & & & SBS & 3 & 0.2 \\
\hline $20-29$ & 68 & 4.5 & MCS & 1 & 0.1 \\
\hline $30-39$ & 266 & 17.7 & Asthma & 95 & 7.7 \\
\hline $40-49$ & 533 & 35.5 & Atopic dermatitis & 122 & 9.8 \\
\hline $50-59$ & 496 & 33.1 & Rash & 21 & 1.7 \\
\hline $60-69$ & 137 & 9.1 & Hay fever & 335 & 27.0 \\
\hline Education & & & Allergic rhinitis & 186 & 15.0 \\
\hline$<6$ years & 6 & 0.4 & Allergic conjunctivitis & 34 & 2.7 \\
\hline $6-9$ years & 69 & 4.6 & Food allergy & 40 & 3.2 \\
\hline $10-12$ years & 454 & 30.3 & Urticaria & 74 & 6.0 \\
\hline$\geq 13$ years & 966 & 64.4 & Mental illnesses & 34 & 2.7 \\
\hline Other & 5 & 0.3 & Sensitivity of family to air quality and odor & & \\
\hline Family income (yen) & & & Yes & 373 & 24.9 \\
\hline$<3$ million & 329 & 21.9 & Family smoking & & \\
\hline $3-<6$ million & 534 & 35.6 & Yes & 654 & 43.6 \\
\hline $6-<9$ million & 346 & 23.1 & Duration of residence & & \\
\hline $9-<15$ million & 231 & 15.4 & $<5$ years & 268 & 17.9 \\
\hline$\geq 15$ million & 60 & 4.0 & $5-<10$ years & 283 & 18.9 \\
\hline Medical history & & & $10-<20$ years & 461 & 30.7 \\
\hline SBS & 1 & 0.1 & $\geq 20$ years & 488 & 32.5 \\
\hline MCS & 6 & 0.4 & Age of house building & & \\
\hline Asthma & 134 & 8.9 & $<5$ years & 103 & 6.9 \\
\hline Atopic dermatitis & 130 & 8.7 & $5-<10$ years & 158 & 10.5 \\
\hline Rash & 56 & 3.7 & $10-<20$ years & 423 & 28.2 \\
\hline Hay fever & 386 & 25.7 & $\geq 20$ years & 816 & 54.4 \\
\hline Allergic rhinitis & 244 & 16.3 & House construction & & \\
\hline Allergic conjunctivitis & 65 & 4.3 & Wooden & 729 & 48.6 \\
\hline Food allergy & 47 & 3.1 & Material window flame (bedroom) & & \\
\hline Urticaria & 154 & 10.3 & Old wooden sash & 28 & 1.9 \\
\hline Mental illnesses & 76 & 5.1 & Aluminum sash & 853 & 56.9 \\
\hline Smoking & & & Double aluminum sash & 260 & 17.3 \\
\hline Never & 794 & 52.9 & Insulation sash & 144 & 9.6 \\
\hline Quit & 340 & 22.7 & Others & 215 & 14.3 \\
\hline Current & 366 & 24.4 & Insulating glass pane type (bedroom) & & \\
\hline Exposure to tobacco & & & Single & 884 & 58.9 \\
\hline Never & 150 & 10.0 & Double & 427 & 28.5 \\
\hline Rare & 236 & 15.7 & Triple & 11 & 0.7 \\
\hline Sometimes & 567 & 37.8 & Others & 178 & 11.9 \\
\hline Often & 547 & 36.5 & Presence of condensation & & \\
\hline Living experience in a renovated house/new house & & & Yes & 1020 & 68.0 \\
\hline Yes & 1004 & 66.9 & Moisture and musty odor & & \\
\hline
\end{tabular}


Table 1 Participants' characteristics (Continued)

\begin{tabular}{|c|c|c|c|c|c|}
\hline & Number & $\%$ & & Number & $\%$ \\
\hline Headache, heaviness in head, tinnitus & & & Yes & 786 & 52.4 \\
\hline Never & 1185 & 79.0 & Using deodorant and fragrance & & \\
\hline Rare & 193 & 12.9 & No & 392 & 26.1 \\
\hline Sometimes & 78 & 5.2 & Rare & 344 & 22.9 \\
\hline Often & 24 & 1.6 & Sometimes & 439 & 29.3 \\
\hline Always & 20 & 1.3 & Often & 196 & 13.1 \\
\hline Itching, burning, irritation, drying of the eyes & & & Every day & 129 & 8.6 \\
\hline Never & 1189 & 79.3 & Pet & & \\
\hline Rare & 201 & 13.4 & Yes & 429 & 28.6 \\
\hline Sometimes & 82 & 5.5 & Ventilation & & \\
\hline Often & 13 & 0.9 & Less than once/day & 391 & 26.1 \\
\hline Always & 15 & 1.0 & More than once/day & 1109 & 73.9 \\
\hline Irritated, stuffy, or runny nose and irritated or dry throat & & & Frequency of cleaning & & \\
\hline Never & 1023 & 68.2 & Less than once/week & 337 & 22.5 \\
\hline Rare & 279 & 18.6 & More than once/week & 1163 & 77.5 \\
\hline Sometimes & 145 & 9.7 & Residential area & & \\
\hline Often & 38 & 2.5 & Hokkaido & 59 & 3.9 \\
\hline Always & 15 & 1.0 & Tohoku & 74 & 4.9 \\
\hline Cough and sneezes & & & Kanto & 595 & 39.7 \\
\hline Never & 994 & 66.3 & Chubu & 236 & 15.7 \\
\hline Rare & 311 & 20.7 & Kansai & 329 & 21.9 \\
\hline Sometimes & 152 & 10.1 & Chugoku & 80 & 5.3 \\
\hline Often & 30 & 2.0 & Shikoku & 42 & 2.8 \\
\hline Always & 13 & 0.9 & Kyushu, Okinawa & 85 & 5.7 \\
\hline Number of family members & & & Interest in air quality and odor & & \\
\hline 1 & 261 & 17.4 & Yes & 958 & 63.9 \\
\hline 2 & 422 & 28.1 & Knowledge regarding SBS & & \\
\hline 3 & 388 & 25.9 & No & 128 & 8.5 \\
\hline 4 & 302 & 20.1 & Have heard & 778 & 51.9 \\
\hline \multirow[t]{2}{*}{$\geq 5$} & 127 & 8.5 & Aware & 464 & 30.9 \\
\hline & & & Deep knowledge & 130 & 8.7 \\
\hline
\end{tabular}

\section{Pre-SBS}

Table 2 shows the prevalence and characteristics of the pre-SBS group and the features are described as follows. The answers for "occasionally," "often," and "always" for each symptom accounted to 120 (8.0\%) for "headache,"
108 (7.2\%) for eye symptoms, 195 (13.1\%) for nasal symptoms, and 192 (12.9\%) for airway symptoms. One thousand two hundred eighteen people among all the participants answered that they had no or rare symptoms and they were judged as those at low risk of "SBS."

Table 2 Prevalence and characteristics of Pre-SBS group

\begin{tabular}{|c|c|c|c|c|c|c|}
\hline & \multicolumn{2}{|c|}{ Group at low risk of SBS, $n(\%)$} & \multicolumn{4}{|c|}{ Group at high risk of SBS, $n(\%)=$ pre-SBS, 282 (18.8) } \\
\hline & Never & Rare & Sometimes & Often & Always & Total \\
\hline Headache, heaviness in head, tinnitus & $1181(79.1)$ & $192(12.9)$ & $78(5.2)$ & $22(1.5)$ & $20(1.3)$ & $120(8.0)$ \\
\hline Itching, burning, irritation, drying of the eyes & $1187(79.5)$ & $198(13.3)$ & $81(5.4)$ & $13(0.8)$ & $14(0.9)$ & $108(7.2)$ \\
\hline Irritated, stuffy, or runny nose & $1020(68.3)$ & $278(18.6)$ & $144(9.7)$ & $37(2.5)$ & $14(0.9)$ & $195(13.1)$ \\
\hline Cough and sneezes & $991(66.4)$ & $310(20.7)$ & $152(10.2)$ & $28(1.9)$ & $12(0.8)$ & $192(12.9)$ \\
\hline
\end{tabular}


A total of 282 participants $(18.8 \%$ of the total participants; male $45.4 \%$, female $54.6 \%$ ) in this study had at least one symptom and they were considered as a highrisk group and defined as pre-SBS symptoms.

\section{Characteristics of the pre-SBS group}

The results of the binomial logistic regression analysis for participants in the pre-SBS group using objective variables are shown in Table 3 , and the characteristic features are described below.

In model 1 , in which individual characteristics and awareness were the adjustment variables, a significant association was observed for four variables at $p<0.05$. Regarding age groups, based on the youngest group who was age of 20-29 years as the reference, the proportion of participants with pre-SBS in each age group decreased with increasing age: OR for the participants aged 40-49, $50-59$, and $60-69$ years were $0.50,0.26$, and 0.20 , respectively. In addition, with regard to disease history, the probability of having pre-SBS was higher in those with a history of "allergic rhinitis" (OR $=2.52)$ or "mental illness" (OR $=2.25)$. Regarding awareness, the probability of pre-SBS was higher in those with the "interest in air quality and odor" $(\mathrm{OR}=1.51)$. In model 2 , in which residential environment was an adjustment variable, a significant association was observed for six variables at $p<$ 0.05. Particularly, having "a family member with sensitivity to chemical substances and odor" was associated with a high probability of pre-SBS $(\mathrm{OR}=2.32)$. Regarding "duration of residence in the house" using $<5$ years as a reference, a higher "duration of residence" was inversely associated with a higher probability of pre-SBS, indicated by $10-<20$ years $(\mathrm{OR}=0.59)$ and $\geq 20$ years $(\mathrm{OR}=$ $0.53)$. The results also showed that a higher probability of pre-SBS was associated with "condensation status of the house" (OR = 1.61) and "moisture and musty odor" $(\mathrm{OR}=1.97)$. In addition, regarding the frequency of "use of deodorant and fragrance," when the response of "not at all" was set as the reference, the probability of preSBS associated with "use every day" increased (OR = 1.65). Conversely, regarding "frequency of cleaning," when "cleans everyday" was set as the reference, the OR for "less than once/week" was 1.54, indicating a high probability of pre-SBS. The other eight items had a significant relationship with pre-SBS in the final model (model 3), with individual characteristics, awareness, and personal environment as adjustment variables. In particular, the probability of pre-SBS declined with increasing age. However, for medical history, in addition to having a history of "allergic rhinitis" and "mental disorder," "hay fever" was associated with a high probability of having pre-SBS $(\mathrm{OR}=1.58)$. Conversely, "interest in air quality and odor," "duration of residence in the current house," or frequency of "use of deodorant and fragrance" did not show any significant associations following adjustment.

\section{Discussion}

This study revealed that $18.8 \%$ of all respondents were categorized as pre-SBS based on their experience of "headache" or any symptoms in their eyes, nose, or throat upon entering their current building. Many previous reports have indicated that females are more likely to experience "SBS" or hypersensitivity to chemical substances $[4,34,35]$. There are various reasons for this, including females' generally higher awareness of health [34], a strong feeling of repulsion in response to certain odors [7], and a high exposure to TVOC of females compared with males [8]. The prevalence of "SBS" is higher among females compared with males, regardless of individual, occupational, and building-related factors [36]. However, the current study revealed that the percentage of females and males was $54.4 \%$ and $45.6 \%$, respectively, in the pre-SBS group, which includes individuals who are not diagnosed with "SBS" or "MCS" but who experienced symptoms that were not severe enough to be recognized as symptoms of these conditions. This indicates that males have SBS-specific experiences similar to females. With regard to the age of participants in the pre-SBS group, the highest occurrence of symptoms was observed in younger participants (aged 20-29 years) and 0.5 times in those aged 40-49 ( $p$ $<0.05), 0.3$ times in those aged 50-59 $(p<0.001)$, and 0.2 times in those aged $60-69(p<0.001)$, indicating a significant decrease with increasing age. Previous studies regarding "MCS" and allergies have reported various characteristics regarding age. One study reported a higher occurrence of these conditions in individuals aged $<30$ years [37], and another study reported that these conditions were observed in individuals of all ages [4]. These results which are different from those of the previous study may indicate that certain men and women, including young and old people, are equally sensitive to chemical exposure. Just the number of people who are interested and aware of the symptoms may be different, and those who are interested may be taking action to avoid the risk factors in the environment. This is a limitation of this cross-sectional study, and further investigation is needed. However, "SBS" and "MCS" can develop as diseases following exposure chemical substances, even to low concentrations if the exposure is continuous [32, 33]. Alternatively, the young participants who comprised a high percentage of the pre-SBS group in the current study have a longer life expectancy, so they may suffer from worsening symptoms or the onset of diseases due to exposure over a long period if they remain unaware of their symptoms. This may increase the number of patients with these conditions in the future. In addition, 
Table 3 Results of univariate and multivariate regression analyses for the association of objective variables with pre-SBS

\begin{tabular}{|c|c|c|c|c|c|c|c|c|c|}
\hline & \multicolumn{3}{|l|}{ Charactristics } & \multicolumn{3}{|l|}{ Environment } & \multicolumn{3}{|c|}{ Charactristics + Environment } \\
\hline & Adjusted OR & \multicolumn{2}{|c|}{$95 \% \mathrm{Cl}$} & Adjusted OR & \multicolumn{2}{|c|}{$95 \% \mathrm{Cl}$} & Adjusted OR & \multicolumn{2}{|c|}{$95 \% \mathrm{Cl}$} \\
\hline \multicolumn{10}{|l|}{ Sex } \\
\hline Male & 0.96 & 0.71 & 1.30 & & & & & & \\
\hline \multicolumn{10}{|l|}{ Age } \\
\hline $20-29$ & Ref. & & & & & & Ref. & & \\
\hline $30-39$ & 0.62 & 0.33 & 1.15 & & & & 0.50 & 0.22 & 1.11 \\
\hline $40-49$ & $0.50^{*}$ & 0.27 & 0.90 & & & & $0.46^{*}$ & 0.21 & 0.99 \\
\hline $50-59$ & $0.26^{* * *}$ & 0.14 & 0.50 & & & & $0.26^{* *}$ & 0.12 & 0.57 \\
\hline $60-69$ & $0.20^{* * *}$ & 0.09 & 0.45 & & & & $0.25^{* *}$ & 0.10 & 0.64 \\
\hline \multicolumn{10}{|l|}{ Medical history } \\
\hline Asthma & 1.18 & 0.75 & 1.86 & & & & & & \\
\hline Atopic dermatitis & 0.84 & 0.52 & 1.35 & & & & & & \\
\hline Rash & 1.08 & 0.55 & 2.14 & & & & & & \\
\hline Hay fever & 1.35 & 0.99 & 1.83 & & & & $1.58^{* *}$ & 1.14 & 2.19 \\
\hline Allergic rhinitis & $2.52^{* * *}$ & 1.76 & 3.62 & & & & $2.63^{* * *}$ & 1.85 & 3.74 \\
\hline Allergic conjunctivitis & 0.73 & 0.39 & 1.39 & & & & & & \\
\hline Food allergy & 1.61 & 0.81 & 3.21 & & & & & & \\
\hline Urticaria & 1.07 & 0.69 & 1.67 & & & & & & \\
\hline Mental illnesses & $2.25^{* *}$ & 1.31 & 3.86 & & & & $2.07^{*}$ & 1.16 & 3.68 \\
\hline \multicolumn{10}{|l|}{ Smoking } \\
\hline Never & Ref. & & & & & & & & \\
\hline Quit & 1.15 & 0.81 & 1.63 & & & & & & \\
\hline Current & 1.02 & 0.71 & 1.47 & & & & & & \\
\hline Interest in air quality and odor & $1.51^{*}$ & 1.10 & 2.08 & & & & & & \\
\hline Sensitivity of family members to VOCs and odor & & & & $2.32^{* * *}$ & 1.69 & 3.18 & $2.11^{* * *}$ & 1.53 & 2.92 \\
\hline \multicolumn{10}{|l|}{ Duration of residence } \\
\hline$<5$ years & & & & Ref. & & & & & \\
\hline $5-<10$ years & & & & 0.79 & 0.49 & 1.27 & & & \\
\hline $10-<20$ years & & & & $0.59^{*}$ & 0.38 & 0.92 & & & \\
\hline$\geq 20$ years & & & & $0.53^{* *}$ & 0.34 & 0.84 & & & \\
\hline Condensation in winter & & & & $1.61^{* *}$ & 1.10 & 2.36 & $1.59^{*}$ & 1.09 & 2.34 \\
\hline House construction (excluding wooden houses) & & & & 1.20 & 0.88 & 1.63 & & & \\
\hline \multicolumn{10}{|l|}{ Therma insulation performance } \\
\hline Prior to the 555 standard & & & & Ref. & & & & & \\
\hline Standard S55 & & & & 1.15 & 0.61 & 2.19 & & & \\
\hline Standard $\mathrm{H} 4$ & & & & 1.09 & 0.61 & 1.94 & & & \\
\hline Standard $\mathrm{H} 11$ & & & & 1.85 & 0.90 & 3.78 & & & \\
\hline Moisture and musty odor & & & & $1.97^{* * *}$ & 1.41 & 2.74 & $1.73^{* *}$ & 1.23 & 2.43 \\
\hline \multicolumn{10}{|l|}{ Deodorant and fragrance use } \\
\hline No & & & & Ref. & & & Ref. & & \\
\hline Rare & & & & 0.81 & 0.51 & 1.29 & 0.75 & 0.46 & 1.22 \\
\hline Sometimes & & & & 1.26 & 0.83 & 1.91 & 1.17 & 0.76 & 1.79 \\
\hline Often & & & & $1.65^{*}$ & 1.07 & 2.54 & 1.46 & 0.93 & 2.28 \\
\hline Ventilation less than once/day & & & & 1.11 & 0.81 & 1.52 & & & \\
\hline Cleaning frequency less than once/week & & & & $1.54^{*}$ & 1.06 & 2.23 & $1.60^{*}$ & 1.11 & 2.31 \\
\hline
\end{tabular}

significant at ${ }^{*} p<.05,{ }^{* *} p<.01,{ }^{* * *} p<.001$ 
further attention should be paid to the relationship between other diseases and chemicals in the air, not just "SBS" and "MCS" [38-40].

Analysis using individual characteristics as adjustment variables (model 1) revealed the significant association between the pre-SBS group and a history of "allergic rhinitis," a history of "mental illness," and the presence or absence of an "interest in air quality and odor." Many studies have reported a relationship between a history of these diseases (allergies and "mental illness") and "SBS" and "MCS." For example, one report has suggested that the estimated prevalence of "MCS" is higher in patients with allergic diseases than in patients who did not have allergic diseases [37]. There is another report that indicated similar results on the association between psychological factors and "SBS" and "MCS" [16] which were observed in the pre-SBS group in this study. Regarding the personal environment, including the residential environment, showed an association with pre-SBS; a significant relationship was seen between the answer of "always" to questions relating to "condensation" status in the house, "moisture and musty odors," frequency of "use of deodorant and fragrance," and insulation efficiency of the house. According to previous studies, the prevalence of "SBS" was higher among individuals living in unsanitary buildings compared with those living in clean buildings [18, 32, 41, 42]; the impact of mold [4145] and "ventilation" on health has also been reported $[46,47]$. The current study indicated that pre-SBS showed patterns similar to those in the abovementioned studies. On the contrary, there was no direct relationship between highly airtight, new buildings and "wooden" houses and pre-SBS. However, considering the result that a residential environment with "condensation" and "moisture/mold" and lifestyle habits such as "frequency of cleaning" of "less than once/week" and heavy fragrance use could lead to an increased risk of pre-SBS, it is clear that individuals should be aware that they should maintain good air quality in their daily life and that living spaces with structures capable of maintaining a continuous, high-quality air environment are both important. To prevent health hazards arising from indoor air and to enjoy a safe and healthy life, it is important to enlighten people and encourage them to regularly clean and ventilate their living spaces, in addition to planning healthy residential environments with mechanical ventilation systems as well as efficient natural ventilation to prevent air retention in buildings. There are some limitations in this study. (1) Causal relationships could not be provided in this study because of the cross-sectional design. (2) This study may be subject to recall bias because the health outcomes, participants' characteristics, and environmental factors used in the assessment in this study were collected on a questionnaire basis and were subjective to the respondents. (3) There may be selection bias, and the participants may not present the population because this survey was registered by an internet survey site.

\section{Conclusions}

We categorized females and males (age, 20-69 years) who had experienced specific symptoms of "SBS" "occasionally," "often," or "always" even without a diagnosis of "SBS" in the pre-SBS group. We then investigated and analyzed associated factors, such as individual characteristics, residential environment, and participants' awareness of relevant facts. Results revealed that the risk of pre-SBS was higher in younger participants, regardless of sex, indicating that it is important to create a good indoor environment. Although recently built, highly airtight and highly insulated "wooden" housing did not show a tendency toward directly increasing the risk of pre-SBS. Maintaining a good indoor environment reduces the risk of pre-SBS; therefore, in addition to educating people, air conditioning and ventilation plans should always ensure a healthy indoor environment.

\section{Abbreviations \\ SBS: Sick building syndrome; VOCs: Volatile organic compounds; MCS: Multiple chemical sensitivity \\ Acknowledgements \\ We thank Crimson Interactive Pvt. Ltd. (Ulatus) www.ulatus.jp for their assistance in the manuscript translation and editing.}

\section{Authors' contributions}

YN and NS contributed to the conception and design of the study. YN contributed to the analysis and interpretation of the data. $\mathrm{YN}$ and $\mathrm{HN}$ contributed to the writing-original draft preparation and reviewing and editing. YN, NS, HN, and KT contributed to the collection and assembly of the data. CM and ET contributed to the final approval of the article. All authors read and approved the final manuscript.

\section{Funding}

This study was supported by Japan Society for the Promotion of Science Grants-in-Aid for Scientific Research (C) Grant Number 18 K13885.

\section{Availability of data and materials}

The datasets generated during and/or analyzed during the current study are not publicly available due to joint research and development with the company but are available from the corresponding author on reasonable request.

Ethics approval and consent to participate

The Research Ethics Committee of the Graduate School of Medicine, Chiba University, approved the protocol of this study (Approval No.2737)

Consent for publication

Not applicable

\section{Competing interests}

The authors declare that they have no conflicts of interest.

\section{Author details}

${ }^{1}$ Center for Preventive Medical Sciences, Chiba University, 6-2-1 Kashiwanoha, Kashiwa, Chiba 277-0882, Japan. ²Department of Bioenvironmental Medicine, Graduate School of Medicine, Chiba University, Chiba, Japan. 
Received: 23 July 2019 Accepted: 12 November 2019

Published online: 17 December 2019

\section{References}

1. Andersson K. Epidemiological approach to indoor air problems. Indoor Air. 1998:8:32-9.

2. Nakaoka H, Todaka E, Seto H, Saito I, Hanazato M, Watanabe M, et al. Correlating the symptoms of sick-building syndrome to indoor VOCs concentration levels and odour. Indoor Built Environ. 2014:23:804-13.

3. Caress SM, Steinemann AC. A review of a two-phase population study of multiple chemical sensitivities. Environ Health Perspect. 2003;111:1490-7.

4. Caress SM, Steinemann AC. Prevalence of multiple chemical sensitivities: a population-based study in the southeastern United States. Am J Public Health. 2004;94:746-7.

5. Hausteiner C, Bornschein S, Hansen J, Zilker T, Förstl H. Self-reported chemical sensitivity in Germany: a population-based survey. Int J Hyg Environ Health. 2005;208:271-8.

6. Carlsson F, Karlson B, Ørbaek P, Osterberg K, Ostergren PO. Prevalence of annoyance attributed to electrical equipment and smells in a Swedish population, and relationship with subjective health and daily functioning. Public Health. 2005;119:568-77.

7. Johansson A, Brämerson A, Millqvist E, Nordin S, Bende M. Prevalence and risk factors for self-reported odour intolerance: the Skövde population-based study. Int Arch Occup Environ Health. 2005;78:559-64.

8. Berg ND, Linneberg A, Dirksen A, Elberling J. Prevalence of self-reported symptoms and consequences related to inhalation of airborne chemicals in a Danish general population. Int Arch Occup Environ Health. 2008:81:881-7.

9. Azuma K, Uchiyama I, Katoh T, Ogata H, Arashidani K, Kunugita N. Prevalence and characteristics of chemical intolerance: a Japanese population-based study. Arch Environ Occup Health. 2015;70:341-53.

10. Hojo S, Mizukoshi A, Azuma K, Okumura J, Ishikawa S, Miyata M. Survey on changes in subjective symptoms, onset/trigger factors, allergic diseases, and chemical exposures in the past decade of Japanese patients with multiple chemical sensitivity. Int J Hyg Environ Health. 2018;221:1085-96.

11. Belachew $H$, Assefa Y, Guyasa G, Azanaw J, Adane T, Dagne $H$, et al. Sick building syndrome and associated risk factors among the population of Gondar town, northwest Ethiopia. Environ Health Prev Med. 2018:23:54.

12. Ministry of Health, Labor and Welfare of Japan: Committee on Sick House Syndrome: Indoor Air Pollution Progress Report. 2002; Volume 4. http:// www.mhlw.go.jp/houdou/2002/02/h0208-3.html. Accessed 4 Apr 2019 (in Japanese).

13. Japanese Ministry of Land, Infrastructure and transport. http://www.mlit.go. jp/jutakukentiku/build/jutakukentiku_house_tk_000043.html. Accessed 4 Apr 2019 (in Japanese).

14. Evidence-based public health guidelines and a practical manual for the prevention of sick house syndrome. http://www.mhlw.go.jp/file/06Seisakujouhou-11130500-Shokuhinanzenbu/0000155147.pdf. Accessed 4 Apr 2019 (in Japanese)

15. Ministry of Health, Labor and Welfare of Japan. https://www.mhlw.go.jp/ content/000470188.pdf. Accessed 4 Apr 2019 (in Japanese).

16. Cui X, Lu X, Hisada A, Fujiwara Y, Katoh T. The correlation between mental health and multiple chemical sensitivity: a survey study in Japanese workers. Environ Health Prev Med. 2015;20:123-9.

17. Binkley KE, Kutcher S. Panic response to sodium lactate infusion in patients with multiple chemical sensitivity syndrome. J Allergy Clin Immunol. 1997; 99:570-4.

18. Gomzi M, Bobic J, Radosevic-Vidacek B, Macan J, Varnai VM, Milkovic-Kraus $S$, et al. Sick building syndrome: psychological, somatic, and environmental determinants. Arch Environ Occup Health. 2007:62:147-55.

19. Nakayama K, Morimoto K. Relationship between, lifestyle, mold and sick building syndromes in newly built dwellings in Japan. Int J Immunopathol Pharmacol. 2007;20:35-43.

20. Klepeis NE, Nelson WC, Ott WR, Robinson JP, Tsang AM, Switzer P, et al. The National Human Activity Pattern Survey (NHAPS): a resource for assessing exposure to environmental pollutants. J Expo Anal Environ Epidemiol. 2001; 11:231-52.

21. Brandner R, Flatscher $G$, Ringhofer A, Schickhofer G, Thiel A. Cross laminated timber (CLT): overview and development. Eur J Wood Prod. 2016:74:331-51.

22. Japanese Ministry of Agriculture, Forestry and Fisheries. http://www.rinya maff.go.jp/j/riyou/goho/english/pdf/02act-on-promotion.pdf. Accessed 4 Apr 2019 (in Japanese)
23. Suzuki N, Nakaoka H, Hanazato M, Nakayama Y, Takaya K, Mori C. Emission rates of substances from low-volatile-organic-compound paints. Int J Environ Sci Technol. 2018;16:4543-50.

24. Kobayashi S, Takeuchi S, Kojima H, Takahashi T, Jin K, Akitsu H, et al. Indoor air pollution in a newly constructed elementary school caused by 1-methyl2-pyrrolidone and texanol emitted from water-based paints. Indoor Environ. 2010;13:39-54

25. Herberth G, Gubelt R, Röder S, Krämer U, Schins RP, Diez U, et al. Increase of inflammatory markers after indoor renovation activities: the LISA birth cohort study. Pediatr Allergy Immunol. 2009;20:563-70.

26. Azuma K, Ikeda K, Kagi N, Yanagi U, Osawa H. Prevalence and risk factors associated with nonspecific building-related symptoms in office employees in Japan: relationships between work environment, Indoor Air Quality, and occupational stress. Indoor Air. 2015;25:499-511.

27. Engvall K, Norrby C, Bandel J, Hult M, Norbäck D. Development of a multiple regression model to identify multi-family residential buildings with a high prevalence of sick building syndrome (SBS). Indoor Air. 2000;10:101-10

28. Mizoue T, Reijula K, Andersson K. Environmental tobacco smoke exposure and overtime work as risk factors for sick building syndrome in Japan. Am J Epidemiol. 2001;154:803-8.

29. Takeda M, Saijo Y, Yuasa M, Kanazawa A, Araki A, Kishi R. Relationship between sick building syndrome and indoor environmental factors in newly built Japanese dwellings. Int Arch Occup Environ Health. 2009;82:583-93.

30. Takayanagi E, Ikaga T, Murakami S, Seike T, Nakano J. Validation of the effectiveness of residential environment assessment tool for health promotion. J Environ Eng. 2011;76:1101-8.

31. Japanese Ministry of Land, Infrastructure, Transport and Tourism. http:// www.mlit.go.jp/common/001134876.pdf. Accessed 4 Apr 2019 (in Japanese).

32. Sick building syndrome. https://www.wondermakers.com/Portals/0/docs/ Sick\%20building\%20syndrome\%20by\%20WHO.pdf. Accessed 4 Apr 2019.

33. Miller CS. Toxicant-induced loss of tolerance--an emerging theory of disease? Environ Health Perspect. 1997;105:445-53.

34. Karvala K, Markku S, Palmquist E, Nyback MH, Nordin S. Prevalence of various environmental intolerances in a Swedish and Finnish general population. Environ Res. 2018:161:220-8.

35. Palmquist E, Claeson AS, Neely G, Stenberg B, Nordin S. Overlap in prevalence between various types of environmental intolerance. Int J Hyg Environ Health. 2014;217:427-34

36. Brasche S, Bullinger M, Morfeld M, Gebhardt HJ, Bischof W. Why do women suffer from sick building syndrome more often than men?--subjective higher sensitivity versus objective causes. Indoor Air. 2001;11:217-22.

37. Jeong I, Kim I, Park HJ, Roh J, Park JW, Lee JH. Allergic diseases and multiple chemical sensitivity in Korean adults. Allergy Asthma Immunol Res. 2014;6: 409-14.

38. Qian Y, Yu H, Cai B, Fang B, Wang C. Association between incidence of fatal intracerebral hemorrhagic stroke and fine particulate air pollution. Environ Health Prev Med. 2019;24:38.

39. Chen J, Jiang X, Shi C, Liu R, Lu R, Zhang L. Association between gaseous pollutants and emergency ambulance dispatches for asthma in Chengdu. China: a time-stratified case-crossover study. Environ Health Prev Med. 2019; $24: 20$

40. Khan MS, Coulibaly S, Matsumoto T, Yano Y, Miura M, Nagasaka Y, et al. Association of airborne particles, protein, and endotoxin with emergency department visits for asthma in Kyoto, Japan. Environ Health Prev Med. 2018;23:41.

41. Burge PS. Sick building syndrome. Occup Environ Med. 2003;61:185-90.

42. Li L, Adamkiewicz G, Zhang Y, Spengler JD, Qu F, Sundell J. Effect of traffic exposure on sick building syndrome symptoms among parents/ grandparents of preschool children in Beijing, China. PLOS ONE. 2015;10: e0128767.

43. Chapman JA, Terr Al, Jacobs RL, Charlesworth EN, Bardana EJ. Toxic mold: phantom risk vs science. Ann Allergy Asthma Immunol. 2003;91: 222-32.

44. Straus DC. Molds, mycotoxins, and sick building syndrome. Toxicol Ind Health. 2009:25:617-35.

45. Saijo Y, Kishi R, Sata F, Katakura Y, Urashima Y, Hatakeyama A, et al. Symptoms in relation to chemicals and dampness in newly built dwellings. Int Arch Occup Environ Health. 2004;77:461-70.

46. Gomzi M, Bobić J. Sick building syndrome: do we live and work in unhealthy environment? Period Biol. 2009;111:79-84. 
47. Smedje G, Wang J, Norbäck D, Nilsson H, Engvall K. SBS symptoms in relation to dampness and ventilation in inspected single-family houses in Sweden. Int Arch Occup Environ Health. 2017;90:703-11.

\section{Publisher's Note}

Springer Nature remains neutral with regard to jurisdictional claims in published maps and institutional affiliations.

Ready to submit your research? Choose BMC and benefit from:

- fast, convenient online submission

- thorough peer review by experienced researchers in your field

- rapid publication on acceptance

- support for research data, including large and complex data types

- gold Open Access which fosters wider collaboration and increased citations

- maximum visibility for your research: over $100 \mathrm{M}$ website views per year

At BMC, research is always in progress. 